\title{
Features of Managers' Personality Psychological Properties Relationship
}

\author{
Guzel Shaukatovna Gabdreeva ${ }^{1} \&$ Alisa Ramilevna Khalfieva ${ }^{1}$ \\ ${ }^{1}$ Kazan Federal University, Tatarstan \\ Correspondence: Guzel Shaukatovna Gabdreeva, Professor of Kazan Federal University, Kremlevskaya Street, \\ 18, 420008, Kazan, Tatarstan. E-mail: khalfieva@inbox.ru
}

Received: September 26, 2014 Accepted: December 8, 2014 Online Published: December 30, 2014

doi:10.5539/ass.v11n7p158

URL: http://dx.doi.org/10.5539/ass.v11n7p158

\begin{abstract}
The aim of this article is researching psychological characteristics of Manager's personality. The leading approach of this research is to show close relationship of gender characteristics and significant features of Managers' personality. It has been shown that the most characteristic qualities of effective managers are communication skills, strong-willed qualities and also abilities to self-setting goals and organization of actions aimed at achieving them. Basic contributors indicating personality are: confidence, competitiveness, autonomy, initiative, self-acceptance and organizational skills. The results of research in this article can be used in the process of the managers' professional training.
\end{abstract}

Keywords: professional activity of manager, comparative and correlation analyses, features, structure and strategic properties of the personality of manager

\section{Introduction}

In today's fast-paced, competitive world, businesses are continually changing. Most of these organizations are on the hunt for the competitive advantage, or a way to strategically move ahead of the competition in the marketplace. However, earning the competitive advantage takes work; goals must be set, plans must be made, people must be motivated and mobilized, resources have to be gathered and distributed, and objectives have to be monitored and assessed (Shekshni, 2003). That is why the need for professional management personnel dictates the need for preparation of effective managers engaged in various fields of activity. The specificity of their professional activities, defined by the subject-to-subject character makes an actual study of psychological characteristics of managerial activity (Karpov, 2003; Gabdreeva \& Khalfieva, 2014). Psychologists has shown that the professional activity of managers of different levels have high tension, cognitive complexity, the need for rapid inclusion in problematic situations and innovation in the workflow, decision making under uncertainty and risk (Makarova, 1981; Meskon, 1991, Knorring, 2001). The psychological characteristics of managerial activities and individual managers have been described. There is no data in the available literature which contains the structure and structural indicators of personality. That is why filling the gap in knowledge was the purpose of this study.

\section{Materials and Methods}

The study involved the successful managers of their different career level: lower level managers, middle level managers and top level managers. As diagnostic methods were used questionnaires: "Communicative and organizational skills" (Fetiskin, 2002), "Express-diagnostics of personal competitiveness" (Andreev, 2009), "Creative potential of the individual" (Fetiskin, 2002), "Masculinity-femininity" (Bem, 1974), "The Scale of psychological well-being" (Ryff, 1995), "The Level of personal risk preparedness - PSK" (Fetiskin, 2002), "Lightweight multi-factor personality questionnaire - SMOL" (Zaicev, 2004), "Questionnaire psychological resistance to stress - OPUS" (Raspopin, 2009), "Motivation for success and fear of failure" (Fetiskin, 2002), "Strong-Willed personality characteristics" (Chumakov, 2006), "Confidence" (Rudestam, 1990). There are 58 indicators were analyzed at this work. 


\section{Results}

Analysis of all studied parameters showed that the average values beyond the average level of General diagnostic scale has only four indicators: "Communication skills", "Organizational skills", "General psychological stability of the individual to stress" and "Initiative".

So, the indicators of a "typical Respondent, representing the average level of the diagnostic scale for these indicators are: communication and organizational tendencies - from 9 to 12 points; General psychological resistance to stress - 127-152 points; initiative - 4-5 points, whereas in the group of managers these figures are equal to: accounted for 14.45 - communicative tendencies; 14,95 - organizing tendencies; 176,85 - General psychological stability of the individual to stress; 6,30 - initiative. Accordingly, communicative and organizational skills, as well as General personal psychological resistance to stress and initiative are the parameters characterizing the sample of managers.

A study of gender characteristics of managers showed that for a sample of men and the sample of women managers is characterized by the manifestation of androgyny (- 0.12 points in women; - 0.18 points for men). This is the most effective in achieving professional success with a skillful combination of the traits of femininity and masculinity.

The next stage of research carried out correlation analysis. It was noted that diagnosed indicators form a coherent structure, since almost all of them are interconnected. The structure is formed by a large number of links (334), that allows us to speak about the degree of its integration. Selected strategic indicators were indicators that have the highest number of linkages in the structure. This: "Certainty is uncertainty", "Competitiveness", "Autonomy", "Organizational skills", "Initiative", "self-acceptance", "Negative self-esteem, General psychological stability" and "Management of environment".

The indicator with the greatest number of correlations with other indicators (6), is "Certainty-uncertainty." This indicator is positively correlated with indicators of "Initiative", "Openness", "Autonomy", "Organizational propensities", "Communicative tendencies", "Personal competitiveness. This may indicate that the more confident the Respondent feels that he is more proactive, actively seeks to accept new ideas and incorporate them into its sphere of thinking, more self-reliant and independent, able to resist the attempts of society to make them think and act in a certain way, competitive, and he has a better-developed communication and organizational skills.

Significant indicator, also has a large number of interconnections is "Competitiveness" (6). Despite the fact that according to the analysis of average values, the specified parameter from a group of managers is average diagnostic scale, the structure of the indicators it is one of the backbone. "Competitiveness" was identified as the relationship (at the level $\mathrm{p} \leq 0,01$ ) with such indicators as "Confidence-uncertainty", "Determination", "Initiative", "Autonomy", "Communication skills" and "Organizational skills". The analysis of these relationships shows that the higher the Manager desires to achieve the goals in terms of confrontation with seeking the same purpose by other individuals or groups, the greater his confidence, determination, the more he takes the initiative in various activities, the more independent and able to resist the attempts of society to make them think and act in a certain way, self-regulating their own behavior and evaluating themselves according to their personal criteria, as well as sociable, tend to be organizational skills.

The indicator of "Autonomy" also correlates with the six indicators: "Certainty is uncertainty, General psychological resistance to stress, Duration and frequency of occurrence of the stressor", "Determination" and "Perseverance" and "Negative self-esteem" ( $p \leq 0,01$ and $p \leq 0,001)$. The Manager is more independent and able to resist the attempts of society to make them think and act in a certain way, self-regulating their own behavior and evaluating themselves according to their personal criteria, so it is more self-confident, decisive, persistent, and it has a higher overall psychological resistance to stress, and specifically, to situations, "stressogenic" which is defined and enhanced long-term, repeated, or chronic nature of the negative impact of a stressor, more sustainable, positive self-esteem and semiprivate personality in contrast to the trends of self-abasement and stress dissatisfaction with those or other aspects of themselves.

The indicator "Organizational skills" also has a significant number of correlations (5) with such indicators as: "Certainty is uncertainty", "Competitiveness", "Initiative", "Motivation of success and fear of failure" and "Vitality" ( $\mathrm{p} \leq 0,01)$. This means that the more the Manager exerts its organizational skills, the more confident, energetic, not afraid of the situation the desire to achieve the goals in terms of confrontation with others, likes to take the initiative in their hands, aimed at the achievement of success under any circumstances. It should be recalled that according to the average values in the group of managers, this figure is a bright feature, since it goes beyond the boundaries of the average values of the diagnostic scale. 
The following figure with a large number of connections (5) is "Creativity". Indicator initiative correlates with indicators of Communicative tendencies", "Confidence " insecurity", "Competitiveness", "Organizational skills", "Masculinity-femininity". The higher the initiative, the more the Manager is certain in itself, less is lost in the new environment quickly finds friends, aims to expand the circle of friends, helps family and friends, takes the initiative in communication, able to make decisions in difficult and unusual situations, likes to organize various activities, persistent and driven, but also achieves the objectives in terms of confrontation. With an indicator of "Masculinity-femininity" initiative revealed a negative relationship. This suggests that the stronger the Manager expressed feminine traits, the lower his rate of initiative. Accordingly, the above appear masculine traits, the higher initiative.

The following analyzing parameters "self-acceptance" is correlated with such parameters as "lack of time", "Uncertainty", "General psychological stability of the individual to stress" $(\mathrm{p} \leq 0.01)$ and the Stability of positive self-worth" $(p \leq 0,001)$. These results indicated that the more positive the Manager refers to himself, knows and accepts a variety of sides, including good and bad qualities, appreciates his past, the more he is resistant to situations limit and lack of time, uncertainty, obscurity, deficiency of personal relevant information, positive self-esteem and self-acceptance of the individual in contrast to the tendency to humiliation and stress of dissatisfaction with these or those aspects of the self, and, in General, more psychologically resistant to stress.

Only three, but the strongest positive relationship was revealed in the indicator Stability of self-esteem" with such terms as "Running around", "Autonomy", "self-acceptance" $(\mathrm{p} \leq 0,001)$. In addition, these indicators are positively correlated with a measure of General psychological stability of the individual to stress" $(p \leq 0,01)$. The analysis of these relationships shows that the higher the degree of stability of positive self-worth and self-acceptance personality characterizing the Manager, the higher its overall psychological resistance to stress, the more power and competence in the management of the environment, it has better controls over all external activities more efficiently, uses the most of opportunities that can capture or create the conditions and circumstances that are appropriate to meet personal needs and achieve goals, more independent, more positive refers to itself and its past, accept yourself for who he is.

The next analyzing parameters "Control environment" also has three relationships with other indicators of the structure. So, there is a strong positive relationship with indicators of "lack of time", "the Stability of positive self-worth" ( $p \leq 0.001)$ and General psychological stability of the individual to stress" ( $p \leq 0,01)$. This means that the more the Manager has the authority and competence in managing the environment, better controls all external activities, effectively uses the most of opportunities that can capture or create the conditions and circumstances that are appropriate to meet personal needs and achieve goals, the higher his resistance to the situations of the time limit and greater resistance positive self-esteem.

\section{Discussions}

One of the most developed areas in foreign psychology is the study of individual careers (Shane, 2002). F. J. Dorn (1992) examines professional career due to the nature of identification of a person in the career and beyond, examining the influence of social and psychological factors on the choice of education and profession. M. Woodcock (2002), and D. Francis, studying professional career, divide it into stages associated with age-related changes of human rights. There is great attention to the named authors give psychological and social problems of career growth, as well as the emergence of various crises career. So Santalainen, E. Voutilaine, Th. Nissinen (1993) studied the difficulties and obstacles facing the workers in mid-career, when at some moment, as they put it, the stage of "fermentation". D.E. Super (1990), interpretes career as a maturation process that considers the determinants of professional self-determination, development of professional self - concept and stages of career development.

\section{Conclusion}

Summarizing the study, we can conclude that the most typical sample of managers are organizational and communication skills, ability to self-willed manifestations, individual goal setting and organization of actions aimed at achieving these goals. The main structure-forming characteristics are: self-confidence, competitiveness, autonomy, initiative, self-acceptance and organizational skills. The results of the study can be considered in the process of professional training of managers.

This draws attention to the close relationship of gender characteristics and significant features of the personality of the Manager, in particular initiative. This allows you to define as a scientific problem finding out the gender of the features contributing to the professional effectiveness of a manager, the solution of which is a separate subject for further investigation. 


\section{References}

Andreev, V. I. (2009). Concurentology. Training course for creative self-development of competitiveness (p. 468). Kazan: Publishing house of the Center for innovative technology.

Bem, S. L. (1974). The measurement of psychological androgyny. J Consult Clin Psychol, 42, 155-162. http://dx.doi.org/10.1037/h0036215

Bentz, V. J. (1990). Contextual issues in predicting high-level leadership performance: Contextual richness as a criterion consideration in personality research with executives. Measures of leadership. New York.

Chumakov, M. V. (2006). Diagnostics volitional personality. Questions of psychology, 1, 169-178.

Dorn, F. J. (1992). Occupational Wellness: The Integration of Career Identity and Personality Identity. Journal of Counseling \& Development, 71(Nov-Dec), 176-178. http://dx.doi.org/10.1002/j.1556-6676.1992.tb02194.x

Fetiskin, I. E. (2002). Socio-psychological diagnosis of personality development and small groups (pp. 263-265). Moscow: Publishing house of IRAN.

Gabdreeva, G. Sh., \& Khalfieva, A. R. (2014). Structure of the psychological properties of the individual Manager. Education and self-development: Kazan, 2, 194-200.

Gaponenko, A. L., \& Pankruhin, A. P. (2000). General and special management (p. 568).

Karpov, A. V. (2003). Psychology of management: Textbook (p. 582). Moscow: Publishing house of Gardariki.

Knorring, V. I. (2001). Theory, practice and art of management (p. 438). Moscow: Publishing group NORMA-INFRA-M.

Makarova, N., Pasahow, N. M., \& Shevtsov, E. (1981). Mathematical SCIENCES. Methods of analysis of correlation structures in psychological and educational research: Psychological services at the University. Kazan: Publishing house of Kazan state University.

Meskon, M., Albert, M., \& Chidori, F. (1992). Fundamentals of management. M.: Publishing house of Business.

Raspopin, E. V. (2009). Questionnaire psychological resistance to stress (OPUS). Psychological diagnosis, 3, 104-122.

Rudestam, K. (1990). Group psychotherapy. Psycho groups: Theory and practice.

Ryff, C., \& Keyes, C. (1995). The structure of psychological well-being revisited. Journal of Personality and Social Psychology, 69, 719-727. http://dx.doi.org/10.1037/0022-3514.69.4.719

Santalainen, T., \& Voutilainen. (1993). E. Result-based Management. M.: PROGRESS.

Shane, E. (2002). In V. A. Spivak (Ed.), Organizational culture and leadership Text. SPb.: Peter.

Shekshni, S. (2003). Leadership in modern business (excerpt from), 3, 68-73.

Socio-psychological foundations of managerial work: The textbook. (2002). Moscow: Publishing house of the Academy: 160.

Super, D. E. (1990). A life-span space approach to career development: Career choice and development. Hillsdale, NJ: Erlbaum.

Woodcock, M. (1991). Liberated Manager Text (TRANS. from English). M: Business.

Zajcev, V. P. (2004). Psychological test SMOL: Actual problems of rehabilitation medicine, 2, 17-19.

\section{Copyrights}

Copyright for this article is retained by the author(s), with first publication rights granted to the journal.

This is an open-access article distributed under the terms and conditions of the Creative Commons Attribution license (http://creativecommons.org/licenses/by/3.0/). 